6

\title{
Handling the unexpected - a case study of computer support for workplace learning in chemical industry
}

\author{
J. Nilsson \\ Department of Informatics, Lund University \\ Ole Römers väg 6 S-223 63 Lund, Sweden. \\ Phone: +46 462228023 \\ Fax: +46 462224528 \\ E-mail: jorn.nilsson@ics.lu.se
}

\begin{abstract}
In general, process control automation affects operator work knowledge and can potentially hamper development of the operators ability to handle production disturbances. In this case study the effects on work knowledge caused by automation at a chemical industry is studied, and possibilities for overcoming negative effects of automation with computer-supported learning are explored. The aim is to develop a learning environment where a continuous dialogue on recurring problems in production can support operators in developing better skills to handle production disturbances.
\end{abstract}

\section{Keywords}

Process control work, automation, computer supported learning, tacit knowledge

\section{INTRODUCTION}

This chapter describes an ongoing case study where the nature of change in work knowledge and work practices caused by automation at a chemical industry is studied, and possibilities for overcoming negative effects of automation with 
computer support for workplace learning are explored. The study is carried out at a division of Perstorp AB, an international chemical industry, called Chemitech.

In studies of work knowledge and consequences from computerisation, the epistemological perspective becomes a crucial issue for what problems are addressed and how the study is conducted. Section two presents an outline of the problems being researched in the case study, and the epistemological perspective applied is described in section three. The perspective is mainly grounded in work from the National Centre for Research on Working Life in Stockholm, which has a long tradition in researching effects on work knowledge from introduction of new technology. One important influence in this perspective is Ludwig Wittgenstein's later philosophy, as it has been interpreted an developed by for instance Kjell Johannessen (1990, 1992), Allan Janik (1990) and Bengt Molander (1992). Space does not allow a comprehensive description, but since it has important implications for how operator work knowledge is understood, a brief outline of the perspective is presented. In section four, examples of different aspects of operator work knowledge at the Chemitech factory are described using the chosen epistemological perspective. Finally, the chapter is concluded with a description of how a learning environment is being organised, including the design of computer support for learning, with the aim of overcoming negative effects from automation on operators abilities to handle production disturbances.

\section{AUTOMATION AT THE CHEMITECH FACTORY}

The problem that is studied can be described as two interrelated parts. The first part concerns the characteristics of operator work knowledge at Chemitech, how it is affected by automation, and the perspectives on operator work knowledge that is held by different actors in the change process. The second part concerns possibilities of overcoming negative effects on operator work knowledge from automation, that are results from decreased contact with the physical production system.

Chemitech produces liquid chemical products, mostly for other branches of Perstorp AB. Out of thirty employees in total, sixteen are process operators divided in three shifts. The production environment is dominated by nine reactor systems where chemicals are produced, and many production processes use exothermic reactions which requires intense supervision. Two of the reactor systems are fully automated, two are partly automated, and the others are operated manually. A job rotation scheme is used with three week periods, where operators switch between the fully automated, partly automated and manual reactor systems. The goal is to have all reactor systems automated in the near future.

\subsection{Effects on work knowledge}

Numerous studies of work in process industry has been conducted before, describing the nature of process operator work and consequences of automation. Two examples of case studies with different perspectives on operator work are Zuboff (1988) and Perby (1995) who both have researched automation in pulp production. Zuboff 
(1988) regards the control room work as detached from the physical production environment, and argue that operators are forced to give up their action-centred knowledge they have developed in manual work, to acquire the more abstract knowledge needed to control a process from a computer system. Perby (1995), on the other hand, argues that the knowledge developed in automated process control is rooted in manual work. She argues that the picture Zuboff (1988) presents, of operators having difficulties in developing the new skills, is only valid just after the automation. According to Perby (1995), learning automated process control in the long term is a matter of reestablishing and maintaining contact with the physical production system, and developing an ability to bridge the gap from the data presented on the screen to the reality on the factory floor. However, there are also, according to Perby (ibid.), remaining long term effects of automation that stems from the operators lack of contact with the physical production environment. In order to detect production disturbances, the operators have to be able to "see through" the representation of the process presented on the computer screen, an ability that is difficult to develop. In particular it is important to be able to differ between real disturbances in the process and errors in values presented on the screen due to hardware malfunctions.

From early interviews and observations, the effects of automation on operator work knowledge at the Chemitech factory seem to be well in line with the results reported by Perby (1995). However, the operator work at the Chemitech factory differs from the case studies described by both Zuboff (1988) and Perby (1995) in that operators at all times have to be prepared to switch to manual operation in the case of power failure or loss of compressed air supply. In these situations a backup system for power and compressed air is started, allowing the reactor systems to be manually controlled for a limited time. Reactors with ongoing production processes are then brought to a stable state using manual operations. In this study it is assumed that this makes it even more important for the operators to maintain contact with the physical production environment. Furthermore, it seems that operators employed in the future, who will have very little training in manual process control, does not have the same opportunity to develop knowledge in manual operations. This implies that, in the long run, the ability to handle critical disturbances in production may be eroded, increasing the risk for accidents. In handling unexpected situations, manual work knowledge and judgmental abilities in particular become crucial. Disturbances and problems may appear in endless variations in the production environment at Chemitech, and constant changes in the production system, with valves replaced or moved in preparation for automating the reactors, currently also adds to the complexity. One aim of the study is therefore to provide a clearer picture of the limits of operators abilities to handle critical production disturbances where the backup system is used.

A number of actors are involved in, or affected by, the changing work conditions at the Chemitech factory. Apart from the operators, production management on different levels, and the programmers designing the computer process control 
system, are directly involved in the change process. There are also other parts of the organisation that are indirectly affected by the changes. The National Centre for Working Life in Sweden has a long tradition in research concerning effects of computerisation on work knowledge. Bo Göranzon (1993) has shown in a number of case studies that the perspective on knowledge held by different actors in the change process strongly affects issues on computer use. Therefore, the perspectives on operator work knowledge held by different actors in the change process at the Chemitech factory will be surveyed in interviews.

\subsection{Supporting learning at work}

The second part of the case study concerns the possibilities of supporting the operators at the Chemitech factory in overcoming the negative effects of automation on their work knowledge. The focus is on exploring different possibilities in organising a learning environment where operators can improve their abilities in handling critical disturbances in production. This involves designing a computer support for documenting recurring production disturbances and simulating problem situations. In order to get a first picture of the work knowledge needs resulting from automation, unstructured interviews with eleven of the sixteen operators were carried out. A summary of the most frequently expressed knowledge needs is presented in table 1 . The results indicate that most operators perceived a need to improve their abilities to handle unexpected situations in production, and in particular situations requiring the backup system to be used. The needs concern knowing what manual operations are needed as well as being geographically well orientated in the different parts of the backup system in the factory building.

Table 1 Areas of perceived knowledge needs according to operators

\begin{tabular}{ll} 
Knowledge area & Number of operators \\
\hline Correct actions in emergencies & 8 \\
Structure of backup system & 6 \\
Handling smaller disturbances & 5 \\
Handling equipment failure & 4 \\
Orientation in factory & 3
\end{tabular}


From the outline of the research problem above, the research questions addressed in the case study can be summarised as follows:

- What is the nature of the knowledge required for judgement, decisions and action in situations with critical production disturbances at the Chemitech factory?

- What perspectives on operator work knowledge are held by the different actors in the change process?

- What is, from an operator view, the most important consequences on work knowledge from automating production at the Chemitech factory?

- What is the nature of the intervention needed to support the operators in reestablishing and maintaining contact with the physical production system, in order to better prepare them for critical production disturbances?

\section{EPISTEMOLOGICAL PERSPECTIVE}

There are often borders drawn between knowledge that can be expressed in language, and knowledge that cannot be articulated. In many cases knowledge that can be articulated is considered more valuable and, in the extreme case, the only interpretation of the concept that is acknowledged. According to Johannessen (1992), this interpretation is grounded in logical positivism, and a demand for the unambiguous formulation and empirical verification of new knowledge, but has roots far back in history, for example Leibniz's dream of an "exact language". To accept such an interpretation brings with it the problem that moral, aesthetics, religion etc. must be disregarded as knowledge, and therefore we need a wider interpretation that is better grounded in our use of the terms "know", "knowing", and "knowledge" in different contexts.

In his development of the knowledge concept, Johannessen sketches three aspects of knowledge covering both explicit and implicit properties: propositional knowledge, practical knowledge, and knowledge of familiarity. The first aspect, propositional knowledge, corresponds to theoretical knowledge, or knowledge that can be explicitly expressed in rules, formulas, or theories. Practical knowledge is the action-oriented knowledge we acquire by participating in a praxis. However, we also learn through others experiences and examples in the same praxis, and we gradually develop a judgement for applying knowledge in new situations, where we recognise a similarity to earlier experienced situations. This is the aspect of knowledge that Johannessen calls knowledge of familiarity, which together with practical knowledge constitutes the tacit aspects of knowledge. Practical knowledge and knowledge of familiarity are the link between propositional knowledge and the praxis where it is applied according to Johannessen (ibid.), and the latter aspect cannot be present without the other two.

Johannessen (1992) uses Wittgenstein's later philosophy to develop and explain the concept of tacit knowledge, focusing mainly on the nature of rule-following. According to Johannessen, examples are the only means to convey tacit aspects of 
knowledge. Wittgenstein points out that language is constituted in praxis, which is evident in aesthetic, moral, and judicial contexts, but this does not necessarily mean constitutive in a conformist sense. When an example of a concept in a praxis is at hand, and where the interpretation of the example is not straightforward, the example has the potential of shifting the established interpretation of the concept. In Johannessen's interpretation of Wittgenstein, the constitutive nature of praxis can therefore be both conserving and progressive. This view of a combination of tradition and progression is also acknowledged by Allan Janik (1990). Using dancing as an example, Janik explains how rule-following behaviour first is learnt through canonical examples, which is shown by someone competent in the praxis. Not until after these constitutive rules have been learnt, can regulative rules and norms be introduced, for example in the form of a notation for the performance of a dance. Janik explains the transitional actions as a result of the constitutive rules being of an analogue nature. Since rule-following behaviour is learnt through imitation, rather than obeying explicit rules, we can find new ways and still be true to the tradition in a praxis. Therefore the constitutive rules can be both canonical and open at the same time, according to Janik (ibid.).

Another similarity between the interpretations of Johannessen and Janik is that they both speak about judgement as an important part of competent action in praxis. When an example deviating from the established tradition is at hand, both reflective and judgmental abilities are required. An important prerequisite for the imitative learning is, according to Janik (ibid.), to know what is relevant to see in a certain example and a certain situation. We must learn this judgement from a competent practitioner who can point to the salient and relevant elements in particular cases. This 'seeing' must be openminded and unconditional. Janik uses the term 'open-ended concepts' as a necessary precondition for learning. This trust between a learner and an instructor is also present in Donald Schön's (1987) description of the learning process as reciprocal reflection between instructor and learner on each others actions. The learner must have confidence in the instructors' reflections and judgement on the behaviour of the learner. In the next section I will try to exemplify some aspects of operator work knowledge and learning at the Chemitech factory, using the epistemological perspective outlined above.

\section{OPERATOR KNOWLEDGE AT THE CHEMITECH FACTORY}

In production at the Chemitech factory, there are written instructions for each product describing how the process should be run, with amounts of raw material, temperatures in different stages, and required values for product quality parameters. On the face of it the operator work seems to be just following the instructions, putting in the right raw materials at proper stages, keeping times and temperatures, and at the end check that the product fulfils the quality requirements, possibly with the need of some minor adjustments. However, the knowledge needed for manually operating a reactor system, and running a production process, is like in most professions by far more complicated than just following instructions. It seems clear 
that the tacit aspects of work knowledge are the most important for the operators at Chemitech. In the following subsections, some examples of different aspects of operator work knowledge are presented, based on work observation and informal interviews, and related to the three aspects of knowledge described by Johannessen (1990, 1992).

\subsection{Propositional knowledge}

Some fundamental principles, for example the relation between pressure and temperature, can be said to constitute the propositional knowledge that the operators need, but they cannot be fully understood outside an activity context, and can only function as an ideal model of how a reactor system works. Other fundamental facts are knowledge about different raw materials, if they are in liquid form or powder, where they are stored, where the manual controls are located on the different reactors etc.

\subsection{Practical knowledge}

The experienced operator uses all his senses in manual operations - looking down into the reactor through a small glass window, listening to flows in pipes, feeling the temperature on a pipe while adjusting a valve, etc. The practical knowledge is clearly expressed for instance in the operations carried out in adjusting for 'vacuum cooling'. By reducing the inlet of air into the reactor, while at the same time pulling air out of the reactor using a pump, the air pressure in the reactor is reduced. This reduces the temperature at which certain chemical reactions take place, which is necessary in many production processes. The operator adjusts a valve to reduce the air pressure, and thereby also reducing the temperature until reaching the level prescribed in the instructions. He does this while carefully listening to the reactor, and while adjusting the valve he switches back and forth between looking at the meters for temperature and pressure. This corresponds to the direct, unreflective activity that characterises practical knowledge in a praxis, or what Schön (1987) calls 'knowing-in-action'.

In line with Johannessens $(1990,1992)$ different aspects of knowledge, and the argument that knowledge cannot be divided into categories or types, Molander (1992) claims that no knowledge can be completely tacit or completely articulated. Instead we move on a scale from tacit to articulated, where non of the extremes has any correspondence to reality. Adjusting a valve to the right level for vacuum cooling requires tacit knowledge, but it can partly be articulated as rules of thumb or heuristics. At each reactor there is a small 'Post-It'-note with approximate settings for different temperatures. These rules of thumb are used by experienced operators as well as novices. In the same way, the instructions for running a process can be perceived as completely articulated, but uses expressions like 'vacuum cooling at 70 degrees in 25 minutes' where the concept vacuum cooling only can be fully understood from within the praxis. However, the instructions are unarticulated in a deeper sense. The operator makes judgements about external 
factors, influencing how the process will be run. The time of year, and the temperature outside affects the temperature of the cooling water going in to the factory (since it is taken from a creek running through the village of Perstorp). By finding out what other process are currently running he also knows the current capacity of cooling water available. He takes all these factors into account in deciding when to start the process in relation to others, and how to run through the different stages.

\subsection{Knowledge of familiarity}

While vacuum cooling is a good example of the tacit aspect practical knowledge, the aspect knowledge of familiarity is harder to get at. It comes into play in new and sometimes unexpected situations. The operator is then forced to improvise based on experiences from similar situations. This is common because of the infinite variations of disturbances in the normal production process, for instance when a valve jams in a certain step in a certain production process in a certain reactor system. Using Donald Schön's (1987) terms, the operator enters into 'reflection-in-action', a dialogue with the situation where the operator alters between actions and reflections of results from action.

Each unexpected situation becomes a new experience that contributes to the development of the praxis of the operators at Chemitech. The ability of doing correct judgements in handling new situations is strongly connected to the knowledge aspect that Johannessen (1990, 1992) calls knowledge of familiarity. But it can also come into play in decisions during ordinary process control work without disturbances. In processes that are difficult to run safely, a 'vacuum reserve' can be prepared in a vessel adjacent to the reactor, ready to be let in to the reactor to quickly reduce the pressure if necessary. This is not in the written instructions, but a precaution established in the operator praxis, and used for instance in hot summer days when cooling capacity is low. The rule for when to set up a 'vacuum reserve' can be said to be constitutive of safe process control, and requires good judgement and knowledge of familiarity from the operator.

Another situation when knowledge of familiarity comes into play is in the adaptation of process instructions which is done when a new product is introduced. New products are developed in a central laboratory separate from the Chemitech factory, and they are also tested there in small scale. At Chemitech the new products are first run in one of the smaller reactors, and later transferred to larger reactors for production in full scale. At this point, the judgement and knowledge of familiarity of the operators becomes very important. Since the products are only tested in small scale at the product development lab, experienced operators often find flaws in the process instructions which leads to adjustments in the instructions. At the product development laboratory, process instructions are written based on trials in volumes of a few litres, and the operators use their experience to adapt the production process to volumes often a thousand times larger. In the ordinary production work operators also make personal adjustments in 
running the processes. These adjustments are often shortcuts that save time for the operator while maintaining product quality, and they seem to be passed on to newer operators in apprenticeship.

\subsection{Learning operator knowledge}

The manual work knowledge has earlier been characterised by craftily skills, and learning through apprenticeship. After a few weeks in apprenticeship a new operator can normally run one reactor system, but it takes several years to reach a level where you can handle most products on all reactors. One reason for the long learning time is differences between the reactor systems in location of the large number of manual controls. More important reasons are the differences in how processes should be controlled in different reactor systems, due mainly to differences in vessel size and cooling system capacity, and differences depending on external factors such as seasonal air temperature variations.

Since only a relatively small part of the operator knowledge can be articulated, taking part in operator praxis is essential in the learning process, and the tacit aspects of knowledge are conveyed by examples pointed out by the instructor. This is in line with Allan Janik's (1990) description of the learning process, where constitutive rules as the basis for the tacit knowledge, are differed from regulative rules, as the basis for knowledge that can be articulated. Regularity in constitutive rules is learnt through imitation, since there are no articulated rules. Learning to adjust the reactor system for vacuum cooling is one example of operations that can only be learnt through imitation in praxis. Janik (ibid.) also uses cooking as an example, which in general seem to be a rather good comparison with the production processes at the Chemitech factory. In cooking, the recipe is not enough to achieve a good result. First you need to learn the basic manual techniques, and they have to be demonstrated since they cannot be articulated in language. When the constitutive rules of cooking are mastered, the recipe forms the regulative rules that guides cooking on a less detailed level. Likewise, the operators learn the basic manual operations through imitation, and only then can they run a process from beginning to end, following process instructions.

Developing knowledge of familiarity is a slower process. By being exposed to a large number of new and unexpected situations, over the years the operators develop judgmental ability based on a large repertoire of examples. However, operator knowledge does not seem to be related to number of working years only. Even experienced operators now and then find themselves in situations which they cannot handle without help from other operators. From conversations and unstructured interviews with the operators, it seems that operator knowledge is perceived as being largely collective. In problem situations operators often rely on experience from the other workers on the shift, and problems are often solved collectively. This view is also supported by data earlier collected by production management to compare how processes are run by the different operators. They concluded that there are small differences within the shifts and larger differences between the shifts when 
running a particular process. One interpretation may be that knowledge tend to stay within a shift, and that the different shifts develop their own traditions in work knowledge.

\section{COMPUTER SUPPORT FOR WORKPLACE LEARNING}

Based on the knowledge needs experienced by operators presented in table 1 , and the findings on operator work knowledge as exemplified in section four, possibilities of overcoming the negative effects of automation with computer-supported collaborative workplace learning are currently being explored. The aim is to organise a learning environment, where operators can work on improving their abilities to handle production disturbances during periods with lower activity in production. A computer support for learning is designed in close cooperation with one of the operators, and implemented as a hypermedia system using Macromedia Director $^{\mathrm{TM}}$, a multimedia authoring tool. It allows operators to build an interactive model of the physical production system, and then describe examples of production disturbances that can be simulated in this model. The aim with the computer tool is to support the operators in reestablishing and maintain contact with the physical production system, as discussed in section two. It is hoped that this will help them to develop better abilities to 'see through' the representation of the process presented in the process control system, and become better prepared to handle production disturbances. Focus is on working with examples of production disturbances as epistemological tools for conveying experience between operators, both within and across work shifts.

An important question is how examples of production disturbances should be represented, for the operators to be able to relate the examples to their praxis. In the Scandinavian tradition of participatory design of information systems, so called mockups have been used to illustrate properties of a system being designed. In a project on computerisation in printing shops from the eighties (Ehn, 1988), a cardboard box was used to represent a desktop laser printer, a piece of equipment that did not exist at the time. The mockup created the right associations for the users involved in the design process, even if it did not have any functionality at all. According to Ehn \& Kyng (1991) mockups become useful when they make sense to the participants '...not because they mirror 'real things' but because of the interaction and reflection they support' (Ehn \& Kyng, ibid., p. 177). The interactive model of the physical production system, and the examples of production disturbances, are represented using digitised photographs from the factory environment. As simplifications of reality, they have the same role for the operators in the learning process, as a mockup has for users in participatory design. The main goal is to stimulate reflection and dialogue on common production disturbances, and let operators relate documented problems to operator work practice in order to find possible flaws in how problems are handled.

The computer tool is organised in two parts: the first part allows the user to build an interactive model of the physical production system, and the second part 


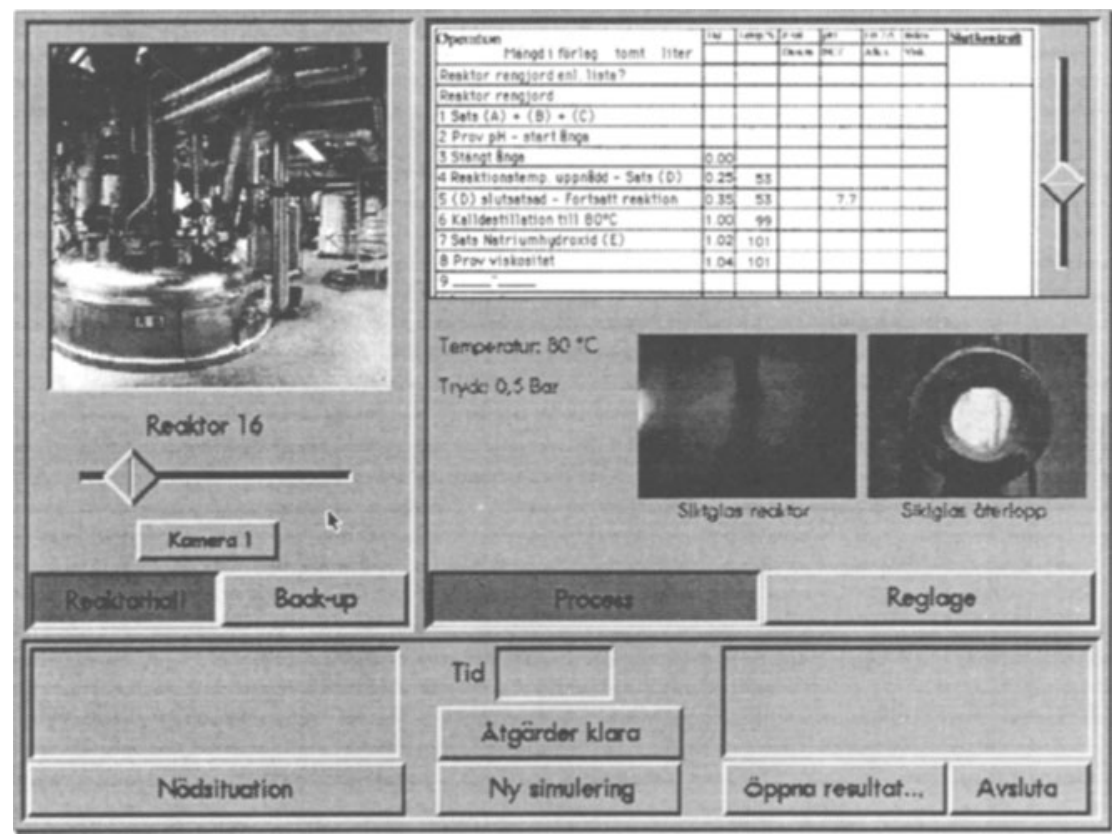

Figure 1. A simulation starts from a randomly generated situation in the factory

provides possibilities to describe specific problems in a production situation. Since small changes are frequently made in the production environment at Chemitech, it is very important that the model is kept up to date at all times. Therefore a digital camera is used, and the images are transferred directly to the computer. After editing, the images are linked in to a hypermedia structure allowing the user to navigate between different parts of the factory by clicking on icons in the images. Components in the machinery can also be zoomed to study details, and for instance valves can be opened or closed by selecting states in a dialogue box. Text descriptions can also be linked to the images for describing functionality, and there is a facility for searching the hypermedia structure, for example by the name of a particular component. In the second part, the state of a production process on a particular reactor system can be described by selecting a step in the written instructions for a process, and filling out values of temperature and pressure. Several such process states can then be aggregated into a production situation in the factory, by adding values for temperature of incoming cooling water and air temperature.

When factory production situations have been set up, problem situations can be simulated using the computer tool. A simulation starts from a production situation in the factory that is either randomly generated or selected (see figure 1). After exploring what processes are currently running on the different reactor systems, 


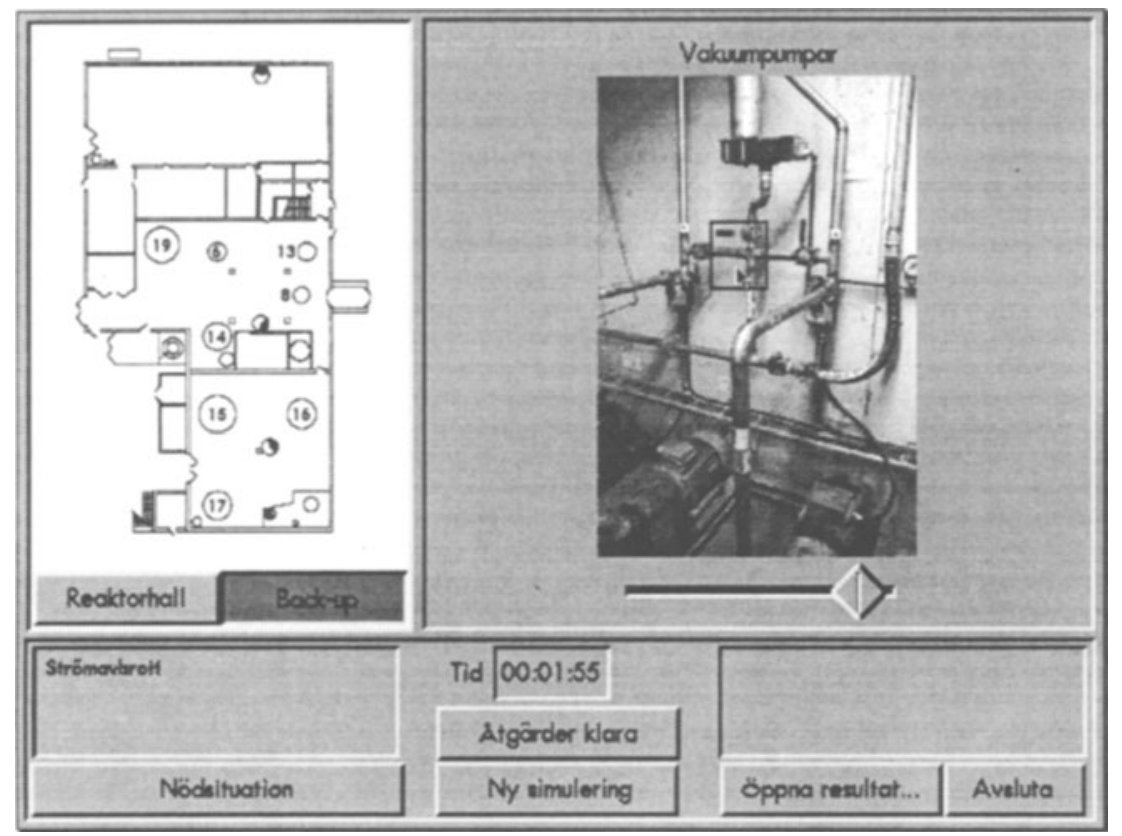

Figure 2: The user interacts directly with the objects displayed

the operator generates a random production disturbance by clicking a button. The appropriate manual operations are then carried out to bring the processes to a stable state (see figure 2). This includes making priorities between the current processes, and invoking the proper parts of the backup system for power, air pressure and cooling water. When all operations are performed, the simulation is stopped by clicking a button, and a log record with time stamps is shown together with recommended operations for the situation at hand (see figure 3 ). The results can then be saved to disk and printed. Finally, there are plans to provide possibilities for feeding the current situation in the factory directly into the simulation environment for simulating disturbances based on real situations. It will also be possible to set different parameters in the simulations controlling the degree of difficulty.

\section{EXPECTED RESULTS}

The computer tool will be studied in use for a period of time, with the aim of developing a form for learning environment based on a continuous dialogue on production disturbances and related problems in operator work practice. Observation of the tool in use is carried out at the Chemitech factory, together with both individual and group interviews with operators. The aim is to document examples that illustrate how the tool can support reflection and discussion on different 


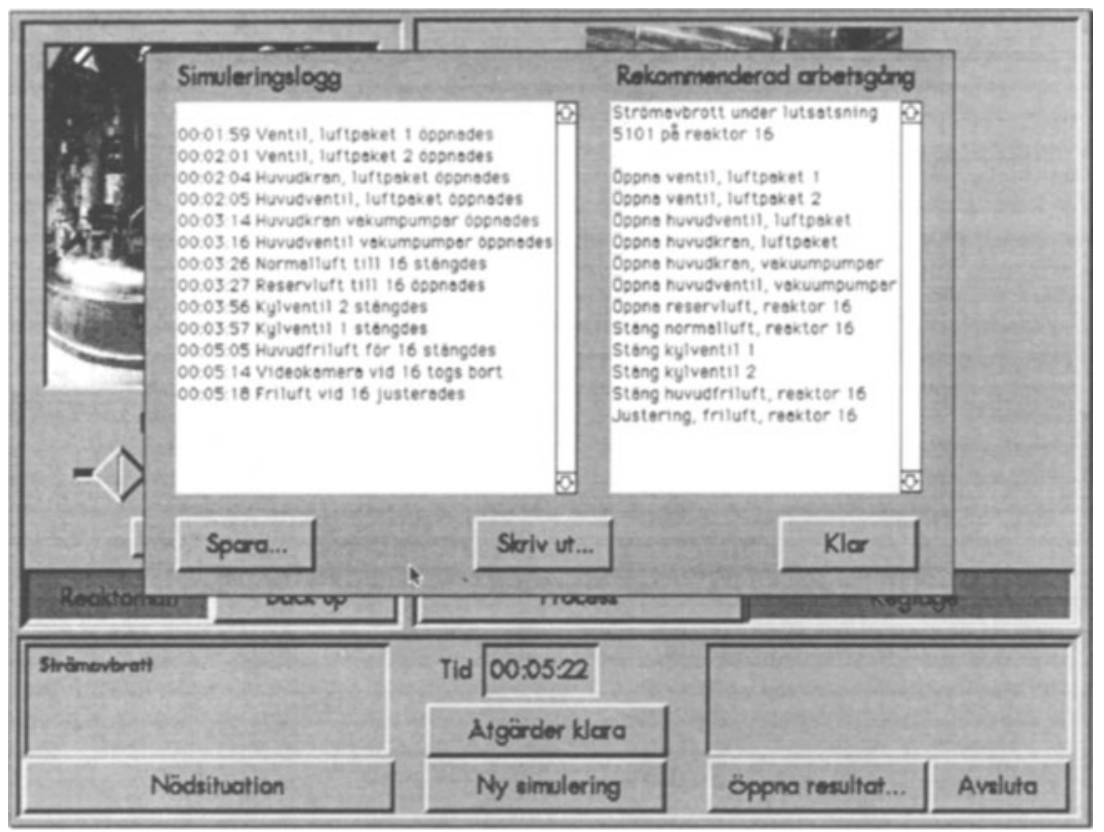

Figure 3: When the simulation is stopped, the logged actions are displayed together with recommended operations.

production disturbances. The main expected result from this case study is an improved understanding of to what extent negative effects of automation on work knowledge can be overcome by organising learning environments with computer support for workplace learning. Other expected results from the study include improved understanding of general consequences caused by automation on operator work knowledge, and in particular abilities to handle critical production disturbances.

\section{REFERENCES}

Ehn, P. (1988) Work-Oriented Design of Computer Artefacts. Arbetslivscentrum, Stockholm.

Ehn, P. and Kyng M. (1991) Cardboard Computers: Mocking-it-up or Hands-on the future, in Design at Work (eds. J. Greenbaum and M. Kyng), Lawrence Erlbaum Associates, Hillsdale, NJ.

Janik, A. (1990) Tacit Knowledge, Rule-following and Learning, in Artificial Intelligence, Culture and Language. On Education and Work (eds. B. Göranzon and M. Florin), Springer-Verlag, Berlin. 
Johannessen, K. S. (1990) Rule-following and Intransitive Understanding, in Artificial Intelligence, Culture and Language. On Education and Work (eds. B. Göranzon and M. Florin), Springer-Verlag, Berlin.

Johannessen, K. S. (1992) Rule-following, Intransitive Understanding and Tacit Knowledge. An Investigation of the Wittgensteinian Concept of Practice as Regards Tacit Knowing, in Skill and Education. Reflection and Experience (eds. B. Göranzon and M. Florin), Springer-Verlag, London.

Molander, B. (1992) Tacit Knowledge and Silenced Knowledge: Fundamental Problems and Controversies, in Skill and Education. Reflection and Experience (eds. B. Göranzon and M. Florin), Springer-Verlag, London.

Perby, M. (1995) Konsten att bemästra en process (in Swedish). Gidlunds förlag, Smedjebacken.

Schön, D. (1987) Educating the Reflective Practitioner. Josey-Bass Publ., San Francisco.

Zuboff, S. (1988) In the Age of the Smart Machine. The Future of Work and Power. Heinemann Professional Publishing, Oxford.

\section{BIOGRAPHY}

Jörn Nilsson is a PhD student at the Department of Informatics, Lund University, where he has lectured since 1988. Currently he is teaching courses in humancomputer interaction at undergraduate and graduate level. His main research interests include effects from computerisation on work knowledge, interaction design, and in particular the design of interactive computer support for workplace learning. 